\title{
Living at the Edge: Local versus Positional Factors in the Long-Term Population Dynamics of an Endangered Orchid
}

\author{
MARÍA B. GARCÍA, ${ }^{*}$ DANIEL GOÑI, $†$ AND DAVID GUZMÁN \\ *Pyrenean Institute of Ecology (CSIC), Apdo. 202, 50080 Zaragoza, Spain, email mariab@ipe.csic.es \\ †LARRE Consultants, S.C. C/Monasterio de Iguácel, $113^{\circ}$ B. 22700 Jaca (Huesca), Spain, email dani.larre@telefonica.net \\ ‡Department of Environment, Aragón Government, Paseo de María Agustín, 36. 50071 Zaragoza, Spain, email dguzman@aragon.es
}

\begin{abstract}
Populations at the margin of geographic ranges of distribution have been considered more vulnerable than central ones, but recent reviews have caste doubt on this generalization. We examined the reproductive and demographic performance of a rare Euroasiatic orchid (Cypripedium calceolus) at its southwesterly range limit and compared our findings with those of previous studies of nine central populations at the center of the orchid's range. We sought to test the central-marginal model and to evaluate factors involved in long-term performance of forest Eurosiberian species with peripheral populations in southern European mountains. We characterized (structure, temporal fluctuations, berbivory, reproductive success, and recruitment at different habitats) four Pyrenean populations of C. calceolus of different sizes (5-3500 ramets) and monitored three of them for up to 13 years. Two quantitative stochastic models (count data and matrix models) were used to assess population trends and viability and the effect of herbivory. Contrary to expectations, and despite the negative effect of sporadic events of herbivory, the peripheral populations we studied (except the smallest one) performed similarly or better than populations occurring in central part of the species' range in terms of reproductive success and population growth rates. Landscape changes over the last 50 years suggest that natural reforestation could be involved in the success of this plant at its southern limit. Forest expansion in the mountain regions of southern Europe may provide new opportunities for plants with geographic distributions centered mainly at bigher latitudes and give some bope for their recovery in future scenarios dominated by biodiversity loss.
\end{abstract}

Keywords count-based models, Cypripedium calceolus, habitat change, herbivory, matrix models, peripheral populations, reproductive success, stochastic population growth rate

Viviendo en el Borde: Factores Posicionales versus Locales en la Dinámica Poblacional a Largo Plazo de una Orquídea en Peligro

Resumen: Las poblaciones en el margen de sus rangos de distribución geográfica han sido consideradas más vulnerables que las centrales, pero revisiones recientes ban generado dudas sobre esta generalización. Examinamos el funcionamiento reproductivo y demográfico de una orquídea Euroasiática rara (Cypripedium calceolus) en su límite suroccidental y comparamos nuestros resultados con los de estudios previos de nueve poblaciones en el centro de su rango de distribución. Buscábamos probar el modelo central-marginal y evaluar los factores involucrados en el funcionamiento de especies Eurosiberianas forestales con poblaciones periféricas en las montañas del sur de Europa. Caracterizamos (estructura, fluctuaciones temporales, berbivoría, exito reproductivo y reclutamiento en diferentes bábitats) cuatro poblaciones pirineas de C. calceolus de tamaños diferentes (5-3500 vástagos) y monitoreamos tres de ellas hasta por 13 años. Dos modelos 
estocásticos cuantitativos (datos de conteos y modelos matriciales) fueron utilizados para evaluar las tendencias y la viabilidad poblacional y el efecto de la berbivoría. Contrariamente a lo esperado, y no obstante el efecto negativo de eventos de herbivoría esporádicos, las poblaciones periféricas estudiadas (excepto la más pequeña) funcionaron similarmente o mejor que las poblaciones de la parte central del rango de distribución de la especie en términos del éxito reproductivo y las tasas de crecimiento poblacional. Los cambios en el paisaje en los últimos 50 años sugieren que la reforestación natural pudiera estar involucrada en el éxito de esta planta en su límite sureño. La expansión de bosques en las regiones montañosas del sur de Europa puede proporcionar nuevas oportunidades para plantas con distribuciones geográficas centradas principalmente en latitudes altas y dar esperanzas para su recuperación en escenarios futuros dominados por la pérdida de biodiversidad.

Palabras Clave: cambio de hábitat, éxito reproductivo, Cypripedium calceolus, herbivoría, modelos basados en conteos, modelos matriciales, poblaciones periféricas, tasa de crecimiento poblacional estocástica

\section{Introduction}

Populations at the periphery of species' geographical ranges are valuable from an evolutionary point of view and will be important to the survival of species under climate change (Lesica \& Allendorf 1995; Hampe \& Petit 2005). Peripheral populations are usually considered more vulnerable compared with populations occurring at the center of a species' range because of their isolation and restriction to marginal habitats. Among plant species, results of some comparative studies between peripheral and central populations show that peripheral populations have reduced fertility or survival, lower density, or higher demographic variability (Nantel \& Gagnon 1999; Dorken \& Eckert 2001; Jump \& Wookward 2003), whereas the results of other studies do not (Lammi et al. 1999; Angert 2006; Samis \& Eckert 2007). In addition, extensive reviews attempting to find general rules show that patterns such as the "abundant center" may not be as common as thought (Sagarin \& Gaines 2002; Sagarin et al. 2006). Evidence is lacking on which to base generalizations about the nature and the causes of differences between central and peripheral populations and the vulnerability of the later.

Generalizations made on the basis of the centralmarginal model are difficult because the approaches and spatial contexts used in studies varied and researchers often analyzed partial fitness components (fertility, density, genetic diversity, etc.) that may not be representative of population trend or vulnerability (Menges \& Dolan 1998; Lammi et al. 1999). In addition, range-wide studies designed to test the theoretical model are scarce (Sagarin et al. 2006), meaning that comparisons made on the basis of just one or a few pairs of central-peripheral populations might result from general rules or particular local factors. To confirm or reject the assumed worse performance and higher vulnerability of peripheral populations, an extensive and integrative approach that compares their population dynamics with the population dynamics of central populations over the widest spatiotemporal context is needed. The effect of population attributes (e.g., population size or structure) or the particular conditions where populations occur (e.g., competition, herbivory) should be taken into account to separate the role of local and positional factors that are driving populations.

We explored the central-peripheral rule by examining the reproduction, demography, and population dynamics of the lady slipper (Cypripedium calceolus). We compared populations at the species' southwesternmost absolute limit with previous results for populations in central and northern Europe (Fig. 1). The lady slipper is a long-lived, clonal orchid, occurring mostly in semishade in woods and meadows across Eurasia (Hultén \& Fries 1986). Its abundance, however, has declined sharply over much of its range, and regional and national extinctions have been reported over the last two centuries (Terschuren 1999; Kull \& Hutchings 2006). Such negative qualitative trends are higher near the limits of the distribution and lower in the taiga regions of Baltic and Scandinavian countries (Terschuren 1999; Nicolè et al. 2005). The Spanish face of the Pyrenees constitutes the absolute southwestern limit of the lady slipper's distribution range, where populations occur in eight localities (Terschuren 1999; M.B.G., personal observation). Over the last 13 years we monitored four populations of dramatically contrasting size to explore to what extent, and in which way, peripheral populations of this species could be more vulnerable than the central ones. We compared our results with results from previous long-term demographic studies carried out in Estonia and Poland, where the largest and best-preserved populations occur.

To get the most-complete view of the species situation in the studied area, we used a three-level monitoring approach (Menges \& Gordon 1996). First, we checked species occurrence with repeated visits to all localities that had been reported with or without documented proof of lady slipper presence (preliminary results in García et al. (2002)). Second, we conducted annual censuses within populations to check fluctuations in population size. Third, we performed a detailed demographic study of the two largest populations by following ramets in permanent plots and applying two quantitative assessments of population trends (count-based models [CBMs] - for long-term monitoring [Morris \& Doak 2002] 


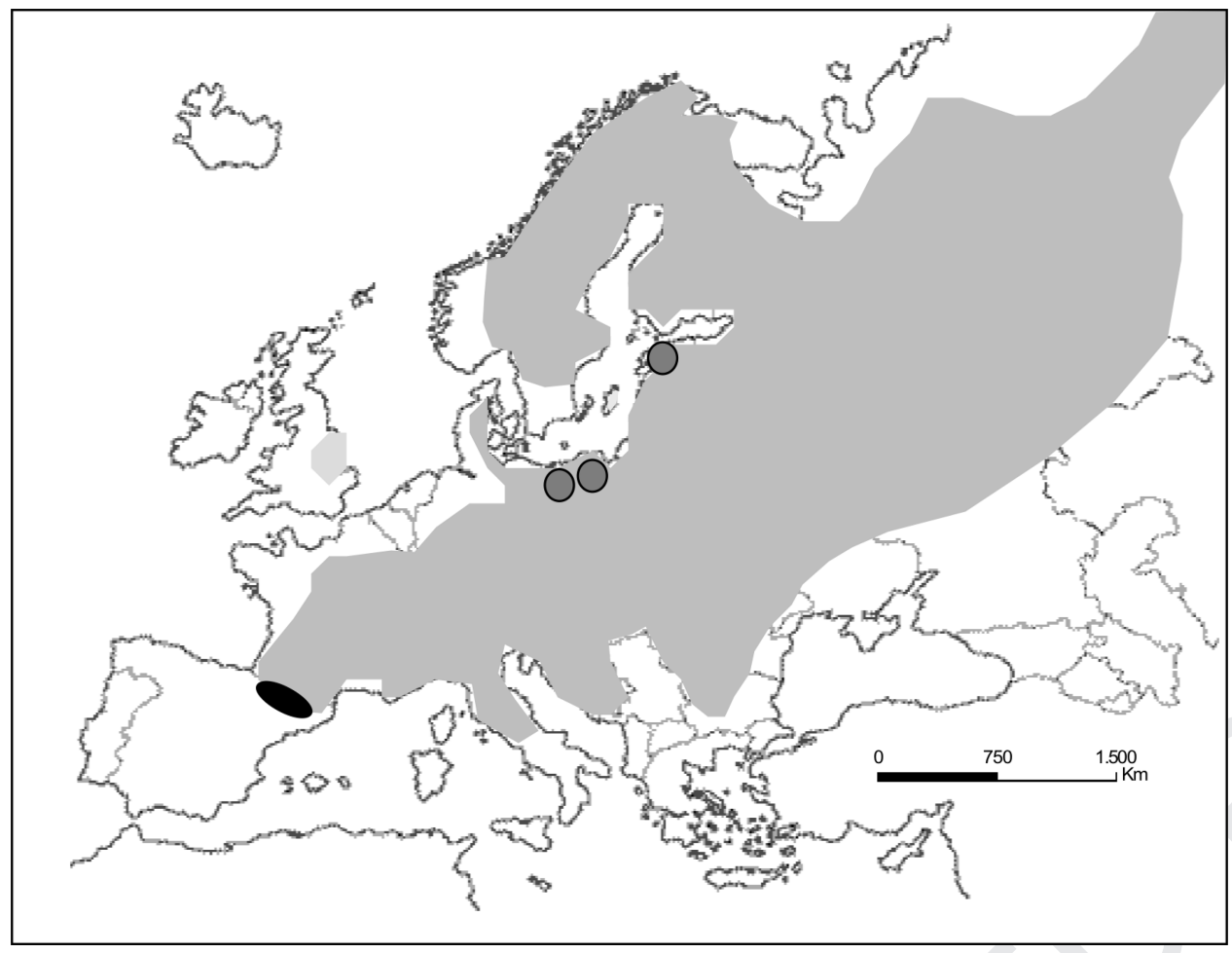

Figure 1. Overall

distribution of lady slippers (Cypripedium calceolus) in Europe (dark gray dots, area of the nine Polish and Estonian central populations, where population dynamics were modeled [Table 2]; black area, location of the four peripheral populations in this study).

and matrix models-for short-term monitoring [Caswell 2001]). We used stochastic models to estimate population trends and risk of extinction and to assess the effect of herbivory. Results were compared with those reported elsewhere for central populations.

\section{Methods}

\section{Legal and Ecological Context of the Species}

The lady slipper is an emblematic plant from a conservation point of view. It is included in Appendix II of the Habitats Directive of the European Union (European Community Council Directive 92/43/EEC), classified as endangered on the IUCN (International Union for Conservation of Nature) Red List (IUCN 2001), and protected after its inclusion in regional catalogues of threatened species (Terschuren 1999). Its distribution in the Iberian Peninsula is restricted to the Pyrenees, where its southwesternmost populations occur. The European Union and the Regional Government of Aragón have funded a long-term monitoring program of these populations since 1997. We repeatedly visited all locations of the species that had been published and reported verbally by naturalists, photographers, and forest keepers and searched the surroundings to verify occurrence of the species at four locations (Table 1).

Populations occurred in three valleys of the Pyrenees (Tena, Ordesa, Pineta; Table 1). They were inside or along the border of mixed forests (Pineta: alluvial for- est on floodplains, over 12 tree species), beech forests (Sallent, Ordesa), more-open grassland habitats (Sallent, Tormosa), and areas with Pyrenean willow bush (Tormosa). The forest at Pineta was the least dense population; it contained more gaps than Sallent and Ordesa, and was flooded occasionally. The minimum and maximum lineal distance among populations was 2.3 and $27 \mathrm{~km}$, respectively.

\section{Demographic and Reproductive Parameters}

To estimate population sizes, we established a number of monitoring plots of different sizes in which we counted shoots (ramets) every year starting in 1997 ( $n=216$, 232, 48, and 2 plots at Sallent, Pineta, Tormosa, and Ordesa, respectively). We counted ramets because, in most cases, the spatial dispersion of shoots made it impossible to identify genets. Each plot was assigned to one of the following habitats: forest, grassland, and semishade. Most of the semishade plots at Sallent were located in the grassland near the forest when the study started, but these plots became more shady due to the fast growth of shrubs and trees. We classified each ramet as reproductive or vegetative on the basis of the presence of flowers or fruits (censuses were carried out in June-July). We revisited populations in August after the fruit ripened in and calculated fruit set (ratio of fruits to flowers) for each habitat, population, and year. We examined a total of 12,542 flowers. 
Table 1. Demographic and reproductive descriptors of the four populations of lady slippers (Cypripedium calceolus) studied in the Spanish Pyrenees.

\begin{tabular}{|c|c|c|c|c|c|c|}
\hline Population (m asl) & $\begin{array}{c}\text { Main } \\
\text { babitat }\end{array}$ & $\begin{array}{l}\text { Years of } \\
\text { monitoring }\end{array}$ & $\begin{array}{c}\text { No. of } \\
\text { ramets (\%) }\end{array}$ & $\begin{array}{l}\text { Flowering } \\
\text { plants (\%) }\end{array}$ & $\begin{array}{l}\text { Mean percent } \\
\text { fruit set }(S D)\end{array}$ & $\begin{array}{c}\text { Annual } \\
\text { recruitment }(S D)^{a}\end{array}$ \\
\hline \multirow[t]{4}{*}{ Sallent (1440-1650) } & & 1997-2009 & 3583 & 38 & $21(8)$ & \\
\hline & Forest & & $1716(49)$ & 23 & $18(8)$ & $0.25(0.12)$ \\
\hline & Semishade & & $1001(29)$ & 49 & $24(10)$ & $0.71(0.51)$ \\
\hline & Grassland & & $766(22)$ & 60 & $25(11)$ & \\
\hline \multirow[t]{3}{*}{ Pineta (1180-1250) } & & & 1854 & 19 & $50(16)$ & \\
\hline & Forest & 1999-2009 & $1559(84)$ & 12 & $53(14)$ & $0.41(0.29)$ \\
\hline & Semishade & 2004-2009 & 295 (16) & 58 & $19(12)$ & \\
\hline Tormosa (1890-1960) & Grassland & 2005-2009 & 492 & 66 & $11(7)$ & \\
\hline Ordesa (1330-1360) & Forest & 1999-2009 & 5 & 0 & - & 0 \\
\hline
\end{tabular}

${ }^{a}$ Average per adult individual from matrix-model plots.

\section{Count-Based Population Dynamic Analysis}

We used a CBM at sites with the largest populations (Sallent and Pineta). On a yearly basis, from spring 1999 onward, we recorded the number of ramets in a number of plots ( $n=103$ and 72 at Sallent and Pineta populations, respectively; hereafter CBM plots). New groups of plants were discovered over the study period in both populations (contained in the remaining monitoring plots up to the total mentioned in the previous paragraph), but they were not included in the models.

The ratio of the number of ramets $(N)$ counted in sequential years $(t$ and $t+1)$ in CBM plots was used as an estimation of the population growth rate $\left(\lambda_{t}=N_{t+1} / N\right)$. From the distribution of $\log \lambda$ obtained for each population or habitat (Sallent forest, Sallent grassland [included grassland and semishade areas], and the Pineta forest, hereafter $\mathrm{Sf}, \mathrm{Sg}$, and $\mathrm{P}$, respectively), we tested for density dependence, temporal trend, autocorrelation, and skewness (to ensure assumptions required for our CBM analysis were fulfilled), and then we calculated the stochastic population growth rate (from the logarithm of the geometric mean: $\log \lambda_{G}$ ) and the $95 \%$ CI (from the variance, $\sigma^{2}$ ). A count-based population viability analysis (PVA) was performed in which we considered 30 and 100 ramets as quasi-extinction thresholds to estimate the risk of extinction in the next century. A detailed description of this method is provided in Morris and Doak (2002). Population fluctuations were estimated by calculating the coefficient of variation (CV) of the number of shoots in CBM plots over time.

\section{Matrix Models}

Long-term censuses are the basis of CBMs, which seem a priority for detecting overall trends and the magnitude of fluctuations of populations of long-lived plants. Matrix models, however, constitute a unique tool to evaluate the effect of particular factors that are thought to be important for the future and management of populations and to check which processes constitute real conservation targets. In contrast to CBMs, for the matrix models
(MM) ramets of all sizes were examined individually over a number of years and grouped into classes of similar performance to estimate the vital rates (fecundity, growth, survival). In this individual-based monitoring, each year we searched for new recruits and small ramets that could pass unnoticed during the annual censuses in the large plots.

To build the matrix models, we monitored plants within eight and six small plots $\left(1 \mathrm{~m}^{2}\right.$ each) in Sallent forest (Sf) and grassland (Sg), respectively, and within one large plot in Pineta ( 3 ha because density was much lower here). The Sallent plots contained 646 ramets (368 and 278 in forest and grassland, respectively), and the Pineta plots contained 603 ramets. Each ramet in a plot was numbered and mapped at the beginning of the study and relocated in August each year. We recorded them as alive or absent in each visit, counted the number of leaves, and measured length and width of the largest leaf. New recruits were mapped, numbered, and included in the data set irrespective of their origins (sexual or asexual). At Pineta a subsample of five plots that, when added together totaled $15 \mathrm{~m}^{2}$, was used to detect new shoots and calculate recruitment rate.

We constructed size-based transition matrices for each year for the two habitats of Sallent and the Pineta populations (see Caswell 2001 for a complete description of the method). To structure the life cycle of the species, we defined six life-cycle classes based on overall size of ramets, probability of flowering, and dormancy (Fig. 2). Length and width of the largest leaf was used to establish thresholds for classes with the aim of obtaining at least 20 ramets per class and classes that contained ramets of similar age or reproductive status in both populations. Ramet weight correlated to the largest leaf size $\left(r^{2}=\right.$ 0.97 and $p<0.0001, n=29$ ). The smallest class (SMT, $\leq 50-\mathrm{mm}$ long) included most of the new recruits in Sallent. The small class (SM, $>50 \mathrm{~mm}$ but $\leq 80-\mathrm{mm}$ long and $\leq 30$-mm wide) contained most new recruits in Pineta. Intermediate-sized ramets (I, $>80 \mathrm{~mm}$ but $\leq 100-\mathrm{mm}$ long and $>30-\mathrm{mm}$ wide or $>100-\mathrm{mm}$ long and $\leq 45-\mathrm{mm}$ wide) are mostly juvenile plants, and there were only a few 


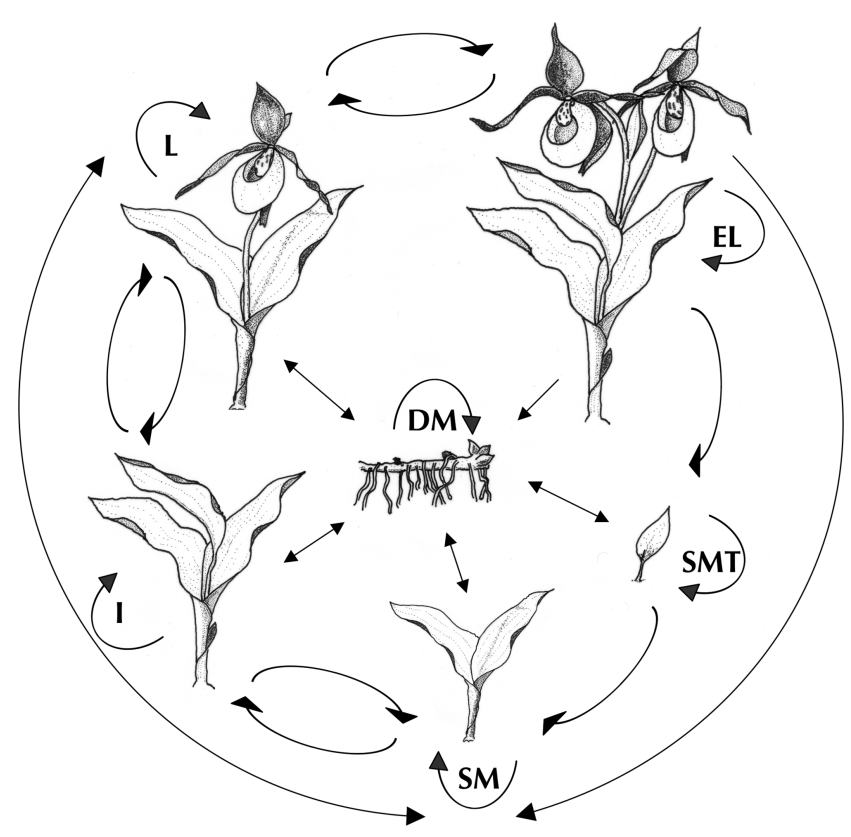

Figure 2. Life cycle of the lady slipper (Cypripedium calceolus) as it corresponds to the average matrix of Pineta (1997-2003) There are six stages in the life cycle: SMT, smallest; SM, small; I, intermediate; L, large; $E L$, extra large (only in Pineta); DM, dormant. See text for further details on bow classes were defined and model setting. Arrows represent transitions among classes, and only values $>0.05$ are depicted.

adults in Pineta and the Sallent grassland. The large class (L, $>100 \mathrm{~mm}$ but $\leq 160$-mm long and $>45$ - $\mathrm{mm}$ wide) contained all the reproductive ramets in Sallent forest, most of the grassland, and most reproductive plants in Pineta. Another class corresponding to the "extra large" ramets (EL $>160$-mm long) occurred only in Pineta. Because there were few dormant plants, only one dormant class was included in the model irrespective of the size of ramets reappearing after dormancy ( 1 or 2 years). If ramets were absent in two successive years of monitoring, we considered the plant dead. This slightly overestimated mortality (four ramets were dormant longer than 2 years at the Pineta population), but we preferred to take a conservative approach.

The sexual or asexual origin of new recruits is almost impossible to distinguish; the latter is much more common than the former (Kull 1995). As is typical of orchids, lady slipper seeds germinate only after a symbiotic relationship with a fungus is established. A subterranean protocorm develops, and it may take a few years after germination for the first green leaf to appear above the surface (Kull 1995). Given the lack of reliable information on this process, the small fluctuations of population structure, fecundity, and recruitment over years, and the low influence of recruitment on population dynamics in long-lived species (García et al. 2008), we decided not to include this subterranean phase as an independent class in the model. To support the validity of our model, we tested the potential importance of the subterranean phase by creating another model that included it (Pineta forest, 2001-2002). Eight scenarios were generated by assigning two contrasting values to the three transitions involved in the subterranean class to cover feasible information obtained in the field, in vitro, or from other papers: (1) $1-10 \%$ of the 5000 seeds/fruit (personal data) were viable and fall down into proper microhabitats (i.e., entered the subterranean class); (2) $0.0001-1 \%$ of those seeds germinated and survived as protocorms over 3-7 years (i.e., stasis); and (3) $1-10 \%$ of subterranean protocorms produced new ramets (i.e., moved into another class). The four pairs of deterministic lambdas resulting from varying transition -2 other values being equalresulted in differences of $\lambda$ as negligible as 0.0003-0.001. Thus, new recruits (whatever their sexual or asexual origin) appearing within the monitored areas were incorporated into the life cycle in the simplest way by assigning their origin to the classes containing adult plants (I and $\mathrm{L}$ in Sallent, plus EL in Pineta) according to their increasing capacity to produce offspring $(0.33$ and 0.67 of new ramets originated from I and $\mathrm{L}$ ramets in Sallent, and 0.17, 0.33 , and 0.5 originated from I, L, and EL ramets in Pineta, respectively).

Transition rates among classes were calculated yearly to build a total of 15 matrices $\left(\mathbf{A}_{\mathrm{i}}\right)$ characterizing each habitat and year (six in Sf for the 1997-2003 period, five in Sg for 1997-2002, and four in Pineta for 1999-2003; see Supporting Information). To explore which processes (recruitment, stasis, growth, and dormancy) had a high influence on the observed variability in population growth rate between habitats of the same population ( $\mathrm{Sf}$ and $\mathrm{Sg}$ ) or populations sharing the same main habitat (the forest of Sallent and Pineta), we used a retrospective analysis (life table response experiments [LTRE] with a random design; Caswell 2001). We used the mean matrix as representative of each of the situations studied (Sf, $\mathrm{Sg}, \mathrm{P})$ because it reflects the performance of the species under particular environmental conditions. The variability of each matrix element between matrices (taking into account the possible covariance) and sensitivity of the mean matrix to each element were used to decompose the positive or negative contribution of each matrix entry to the variability analyzed (Sf vs. Sg and Sf vs. P). Positive and negative values indicate whether differences among compared elements increased or reduced the lambda variability, respectively. Given that the sum of elements with different signs can diminish the magnitude of the contributions considerably, we present absolute and net values for each process (Jongejans \& de Kroon 2005). In this way we show the total effect and how positive and negative contributions compensate each other.

Finally, the stochastic growth rate $\left(\lambda_{s}\right)$ and an approximate $95 \%$ CI were calculated through a simulation of 
50,000 population-growth increments in which each matrix had the same probability of occurrence. The arithmetic mean and variance of $\log \left(N_{t+1} / N_{t}\right)$ over all pairs of adjacent years were calculated with the Stoch_log_lam routine (Morris \& Doak 2002) in MATLAB 7.5 for Mac.

\section{The Effect of Herbivory}

We visually estimated proportional loss of biomass in each ramet we surveyed. There were four levels of herbivory: 0 , none; 1 , low ( $\leq 20 \%) ; 2$, moderate $(21-60 \%)$; and 3 , intense $(\geq 61 \%)$. At the Pineta population, browsing could be severe because cattle are driven through this area on their way to summer pastures at higher elevation. Two episodes of intense grazing were recorded over the study period, in 2001 and 2008 (once every 5 years). Although the effect of the 2001 herbivory event was included in the 5-year demographic matrix model (running from 1999 to 2003), this is a supposedly negative factor whose intensity and frequency should be taken into account.

The effect of herbivory was assessed in three different ways: by checking whether damaged individuals had similar individual vegetative growth rate (change in size between consecutive years) and flowering probability in the next year as undamaged individuals (analysis of variance and logistic regression respectively); by splitting the 2000-2001 matrix into two different matrices, one just for damaged and another for undamaged plants, which separately replaced the original matrix in the stochastic model; and by doubling the probability of occurrence of the original matrix in the stochastic matrix model. Thus, $\lambda_{s}$ was recalculated for three simulated scenarios: no herbivory (matrix constructed with only undamaged plants), very intense herbivory (matrix contained only damaged plants), and a double frequency of herbivory (two out of 5 years; $p=0.4$ ). The output of the three scenarios was compared with the observed scenario (both damaged and undamaged plants in the matrix, $p=0.2$, and corresponding to 1 out of 5 years).

\section{Results}

Population Size, Structure, and Reproductive Parameters

The four southwesternmost peripheral populations of $C$. calceolus monitored varied considerably in terms of population size (three orders of magnitude), occupancy of different habitats, and fruiting success (Table 1). In the largest population (Sallent), where there was a clear gradient of light among habitats (from shady forest to open grassland), almost $80 \%$ of shoots were located inside or in the border (semishade) of the forest. An increasing proportion of reproductive plants and fruit set were recorded

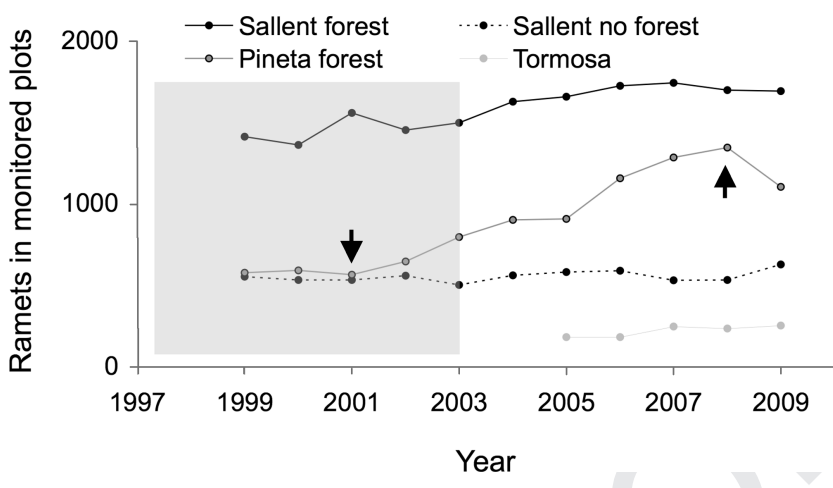

Figure 3. Number of ramets over time in plots monitored for the count-based models (CBM) of three largest populations of lady slippers. Results of individual monitoring for matrix models (MM) are the bottom five shaded points. Arrows show two events of intense berbivory in Pineta.

over this positive gradient of light conditions (Table 1). A similar pattern of lower frequency of reproductive plants in the forest compared with the semishade occurred in Pineta too. The population at the highest elevation (Tormosa, grassland) showed the highest proportion of flowering plants and the lowest reproductive success. No flowering shoot was ever seen in the smallest population (Ordesa) within the forest. Altogether, these results indicate that sexual reproduction is favored in open, lighter places.

\section{Trends and Drivers of Population Growth}

The smallest population showed no clear trend in population growth and had highest temporal variability, fluctuating between 0 and 10 shoots over the last decade $(\mathrm{CV}=0.43)$. The other three populations had stable or increasing population sizes according to CBM (Fig. 3; Table 2). At Pineta forest, population growth rate was the highest, followed by Sallent forest and grassland (not significantly increasing in any case because the 95\% CI included $\lambda_{G}=1$; Table 2). At Sallent grassland, the population growth rate of the "pure grassland" was lower than the "semishade" (0.998 and 1.016, respectively), but not significantly because of the overlapping of both CI. The CBM did not forecast quasi-extinction risk for the next century in either Sallent or in Pineta, even when a threshold population size as high as 100 ramets was factored in.

Matrix models projected stochastic population growth rates significantly higher than one in all cases (Table 2), and always included the value of population growth rate in the $95 \%$ CI produced by CBMs. This means both methods provided consistent results despite differences in length of the monitoring period. Unlike CBM, however, MM projected a faster growth in the grassland (pure grassland + semishade) compared with the forest at Sallent. 
Table 2. Lady slipper (Cypripedium calceolus) locations and habitats where population growth rate and population fluctuations over time were estimated.

\begin{tabular}{|c|c|c|c|c|c|c|}
\hline Location & $\begin{array}{c}\text { Population- } \\
\text { babitat }\end{array}$ & $\begin{array}{c}\text { Years of } \\
\text { monitoring }\end{array}$ & $\begin{array}{c}\text { Coefficient of } \\
\text { variation }\end{array}$ & $\begin{array}{l}\text { Population growtb } \\
\text { rate }(S D \text { or } C I)^{a}\end{array}$ & Metbod $^{b}$ & Reference $^{c}$ \\
\hline $\begin{array}{l}\text { Poland (Kwiecko } \\
\text { lake) }\end{array}$ & Border of lake & 4 & & 0.972 & $\lambda_{\text {(ramets) }}\left(N_{t} / N_{0}\right)$ & $\begin{array}{l}\text { Korczynski and } \\
\text { Sppiewakowski } \\
\text { (1991) }\end{array}$ \\
\hline \multirow{5}{*}{$\begin{array}{l}\text { Western \& Central } \\
\text { Estonia }\end{array}$} & Spruce forest & 17 & 0.37 & 1.067 & $\lambda_{\text {(ramets) }}\left(N_{t} / N_{0}\right)$ & Kull (1995) \\
\hline & Drained forest & 11 & 0.19 & 1.044 & $\lambda_{\text {(ramets) }}\left(N_{t} / N_{0}\right)$ & Kull (1995) \\
\hline & Wooded meadow & 10 & 0.18 & 1.00 & $\lambda_{\text {(ramets) }}\left(N_{t} / N_{0}\right)$ & Kull (1995) \\
\hline & Pine forest & 10 & 0.15 & 1.041 & $\lambda_{\text {(ramets) }}\left(N_{t} / N_{0}\right)$ & Kull (1995) \\
\hline & Swamp forest & 4 & 0.27 & 1.222 & $\lambda_{\text {(ramets) }}\left(N_{t} / N_{0}\right)$ & Kull (1995) \\
\hline \multirow[t]{3}{*}{$\begin{array}{l}\text { Poland (Biebrza N. } \\
\text { Park) }\end{array}$} & Oparzelisko forest & 11 & & $0.992(0.0003)$ & $\lambda_{s \text { (genets) }}-\mathrm{MM}$ & $\begin{array}{l}\text { Nicolè } \\
\quad \text { et al (2005) }\end{array}$ \\
\hline & $\begin{array}{l}\text { Zabudnik shrub } \\
\text { and forest }\end{array}$ & 11 & & $1.008(0.004)$ & $\lambda_{s \text { (genets) }}-\mathrm{MM}$ & $\begin{array}{l}\text { Nicolè } \\
\quad \text { et al. (2005) }\end{array}$ \\
\hline & Pogorza forest & 11 & & $1.010(0.0005)$ & $\lambda_{s \text { (genets) }}-\mathrm{MM}$ & $\begin{array}{l}\text { Nicolè } \\
\quad \text { et al. (2005) }\end{array}$ \\
\hline \multirow[t]{6}{*}{ Spanish Pyrenees } & Sallent forest & 11 & 0.08 & $1.018(0.976-1.062)$ & $\lambda_{G \text { (ramets) }}-\mathrm{CBM}$ & This study \\
\hline & & 7 & & $1.005(1.004-1.006)$ & $\lambda_{s \text { (ramets) }}-\mathrm{MM}$ & This study \\
\hline & Sallent grassland & 11 & 0.06 & $1.013(0.954-1.076)$ & $\lambda_{G \text { (ramets) }}-\mathrm{CBM}$ & This study \\
\hline & & 6 & & $1.046(1.045-1.047)$ & $\lambda_{s \text { (ramets) }}-\mathrm{MM}$ & This study \\
\hline & Pineta forest & 11 & 0.32 & $1.067(0.973-1.170)$ & $\lambda_{G \text { (ramets) }}-\mathrm{CBM}$ & This study \\
\hline & & 5 & & $1.020(1.019-1.020)$ & $\lambda_{s \text { (ramets) }}-\mathrm{MM}$ & This study \\
\hline
\end{tabular}

${ }^{\text {The } 95 \% \text { confidence interval. }}$

${ }^{b}$ MM: matrix model; CBM: count-based model; $\lambda \mathrm{N}_{\mathrm{t}} / \mathrm{N}_{O}$ : population growth rate from total number of ramets at the beginning ( $\mathrm{N}_{O}$ ) and the end $\left(\mathrm{N}_{t}\right)$ of the study; $\lambda_{G}$, geometric lambda from temporal series; $\lambda_{s}$, stochastic lambda.

${ }^{c}$ Kull (1995) and Nicolè et al. (2005) used other methods as well, but we selected the ones closer to ours for comparative purposes or the ones providing bigher population growth estimates. The lambda of the Kwiecko lake population was calculated from 282 shoots in 1989 and 290 shoots in 1986 (Korczynski \& Sppiewakowski 1991).

According to retrospective analysis, differences of vital processes among populations are larger than among habitats (Fig. 4). In both cases variability of the stasis rate was responsible primarily, in absolute terms, for differences in population growth rate, despite its negligible net effect among habitats. Growth and dormancy played a secondary role (relative to stasis) in population differentiation in absolute terms (variance contribution), and their effect was lower for habitat differentiation. Recruitment was the second-most important contribution to habitat differentiation (Table 1), but it was an important to population differentiation (higher in Pineta).

\section{Demographic Effects of Herbivory}

Herbivory was only occasionally detected in the smallest population (Ordesa, 2008), whereas some eaten fruits were detected in Tormosa in 2007, and low levels of leaf herbivory by insects were recorded in the two habitats of the largest population (Sallent; usually $<20 \%$ of damage affecting $<10 \%$ individuals). Pineta, however, suffered two important events of herbivory by mammals: $39 \%$ and $35 \%$ of ramets were intensively damaged (loss of biomass $>60 \%$ ) in 2001 and 2008, respectively.

Plants showing severe signs of herbivory grew significantly less than undamaged plants $(F=129.1$, df $=$
2,205, $p<0.0001$ ), and likewise flowering shoots had a lower probability of flowering in the following year $\left(\chi^{2}=32.8, N=70, p<0.0001\right)$. Despite the overall increasing population trend in Pineta (Fig. 3), matrix models demonstrated that herbivory had a negative effect from a demographic standpoint, irrespective of its intensity within the year (abundance of plants damaged in the matrix) or over the entire study period (frequency of episodes). The stochastic population growth rate $\left(\lambda_{s}\right)$ of the simulated no-herbivory scenario was significantly higher $(1.0215, \mathrm{CI}=1.0210-1.0221)$ than the real one, including one event of herbivory $(1.0198, \mathrm{CI}=$ 1.0192-1.0203), whereas the simulated scenarios of very intense herbivory and double frequency of herbivory significantly reduced $\lambda_{s}(1.0151, \mathrm{CI}=1.0146-1.0158$, and 1.0002, CI $=0.9997-1.0008$, respectively).

\section{Discussion}

The lady slipper is a rare euroasiatic plant that has decreased markedly throughout its range-and in particular near the limits of its distribution-in population numbers and in area of distribution at the regional or local scale (Terschuren 1999). Our results provide detailed information on the size, structure, temporal fluctuations, reproductive success, population dynamics, and effect 
(a)

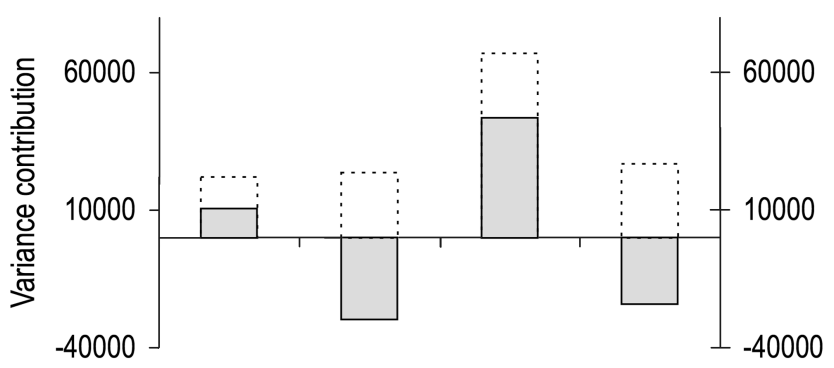

(b)

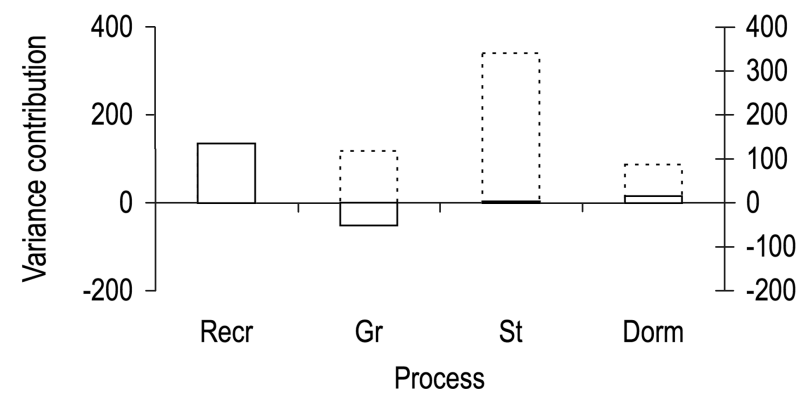

Figure 4. Variance contribution of different processes (Recr, recruitment; Gr, growtb; St, stasis + shrinkage; Dorm, entering into dormancy or reappearing from it) to differences in population growth rate between two different populations of lady slippers with (a) the same main habitat and (b) two different habitats within the same population. Discontinuous outlines correspond to the absolute magnitude of differences, and continuous outlines correspond to the net effect of the variance decomposition (LTRE) (see text for furtber details).

of herbivory of a set of peripheral populations over the last decade. Contrary to expectations derived from the central-marginal model, we could not find evidence that peripheral populations performed worse than populations in central Europe, except for a very small population that had no reproductive plants.

\section{Evolution of Distribution in the Study Area}

The situation of this species in the Iberian Peninsula was alarming in the 1990s because populations in three of the few known locations of the species in the Pyrenees that had been communicated by naturalists decades ago (not supported by empirical evidence such as herbarium sheets or pictures) could not be relocated despite repeated visits. Some past mistake in identification of vegetative plants is possible, as happened for the southernmost location in the Iberian Range (Hultén \& Fries 1986), whose occurrence was supported by a herbarium sample that came from another locality. This is all the historical information available, and it is insufficient to evaluate the possibility of past extinctions and therefore of the possibility of another limit to the distribution that is farther south of the current one.

Nevertheless, the Tormosa population, containing about 500 ramets, was discovered in the last decade, as was an isolated individual $3 \mathrm{~km}$ away from the largest population. New groups of plants have been discovered often in the surroundings of CBM plots at the Pineta and the Sallent populations, so the largest population contained three times more shoots at the end of this study than did previous censuses (Lazare et al. 1987). The situation of the species, therefore, cannot be considered as grave as it seemed to be one decade ago, and our results demonstrate that its status may improve by increasing the survey effort.

\section{Population Dynamics and Local Factors}

Sizes of marginal populations of this study ranged from 10 to more than 3000 ramets, and approximately half of them produced flowers. This range is similar to or higher than in Central Europe (Terschuren 1999). Annual censuses in the CBM plots indicated stable population trends over the last decade. These results agree with those recorded in nine Polish and Estonian populations (Table 2). In fact, the CI of population growth rates (CBM) in the Pyrenees contained all the lambdas published elsewhere except one population in Estonia (Swamp forest, Kull 1995) that was monitored for only 4 years.

The lowest growth rate in our review corresponded to the growth rate in an Estonian wooded meadow (Kull 1995), whereas relatively forested places always resulted in stable or increasing trends (Table 2). In the Pyrenees, the Sallent grassland and the forest resulted in nonsignificant differences in population growth rates according to CBM. The higher value produced by MM compared with CBM in Sallent grassland was due to the high rate of recruitment in the semishade. Count-based methods allowed a much larger area to be sampled because they were less time consuming. However, new seedlings and very small juveniles may go unnoticed when censusing CBM plots, whereas they are recorded in the detailed censuses conducted in MM plots. Both methods, therefore, provided complementary information and should be used in combination or separately, depending on the particular objectives of the study.

Herbivory of shoots and fruits seems to be widespread and can have an important effect on population dynamics (see also Terschuren 1999). Results from experimental defoliations of lady slippers suggest that dormancy is a short-term response that buffers the stress of such biomass loss without increasing mortality risk (Shefferson et al. 2005). The stochastic population growth rate resulting from $\mathrm{CBM}$ and $\mathrm{MM}$ did not indicate that the 
episode of herbivory of 2001 could be considered of concern either (given that $\lambda_{G}$ and $\lambda_{s}>1$ ). However, this is a misleading result. Only comparison of the real scenario with the ones of no herbivory, very intense herbivory, and double frequency of herbivory allowed us to detect the negative effect of browsing at the population level (besides the individual level), which was masked in this case by the high population growth of that population. The hidden detrimental effect of herbivory we discovered would play an important role in the case of stable or declining populations.

\section{Peripheral Position versus Local Factors}

Our results do not support the widespread idea of peripheral populations performing worse than central ones. Despite lady slippers being a nonrewarding orchid, the fruit set was higher than in many other rewarding orchids and also than in the Estonian, Polish, Swedish, and one Danish populations of the same species (Kull 1998; Erneberg \& Holm 1999; Brzosko 2002). Consequently, neither pollination nor the potential for recruitment or for the dispersal of the tiny seeds to new places appeared to be a matter of concern. Besides that, comparison of population fluctuations, tendencies, and extinction risk in central versus peripheral populations of this study did not support the idea of lower population growth rates or higher temporal variability (and therefore higher vulnerability, Menges 1997) at the southern edge.

Which factors might be involved in the unexpected success of the studied peripheral populations? It has been suggested that lady slippers depend on moderate forest disturbances and that alterations of forestry regime and closing of forest canopy are the primary threatening factors (Reier et al. 2005). In the peripheral areas of our study, which were close to the warm and dry Mediterranean climate, the species inhabited mostly mountain forests at mid-elevation and grasslands near the treeline. Habitats in the Pyrenees are evolving rapidly as a consequence of reduction in abundance of cattle that followed profound changes in traditional land use. We observed such processes over the study period because some open areas containing groups of plants at Sallent became noticeably more shaded during this 13-year study. Comparisons of aerial pictures taken 50 years ago with pictures taken recently of the two largest populations showed that grasslands and shrublands were being reforested (Fig. 5). We cannot claim that this forest expansion is the only cause of the stable or positive trend in this species in the Pyrenees, but it seems a logical deduction. This deduction is supported by the higher population growth rate in forest habitats compared with grassland habitat (Sf and Pineta vs. Sg) and by the higher detrimental effect of herbivory in grasslands than in forest habitats. Thus, contrary to our expectations (Reier et al. 2005) forest recovery should promote expansion for a mainly forest-dependent species at its southernmost limit because shade and shelter are being provided at the climatic border, at least during the early stages of succession.

Global changes, and climatic warming in particular, are threatening factors that will have dramatic consequences for biodiversity. The negative effect that colonization of
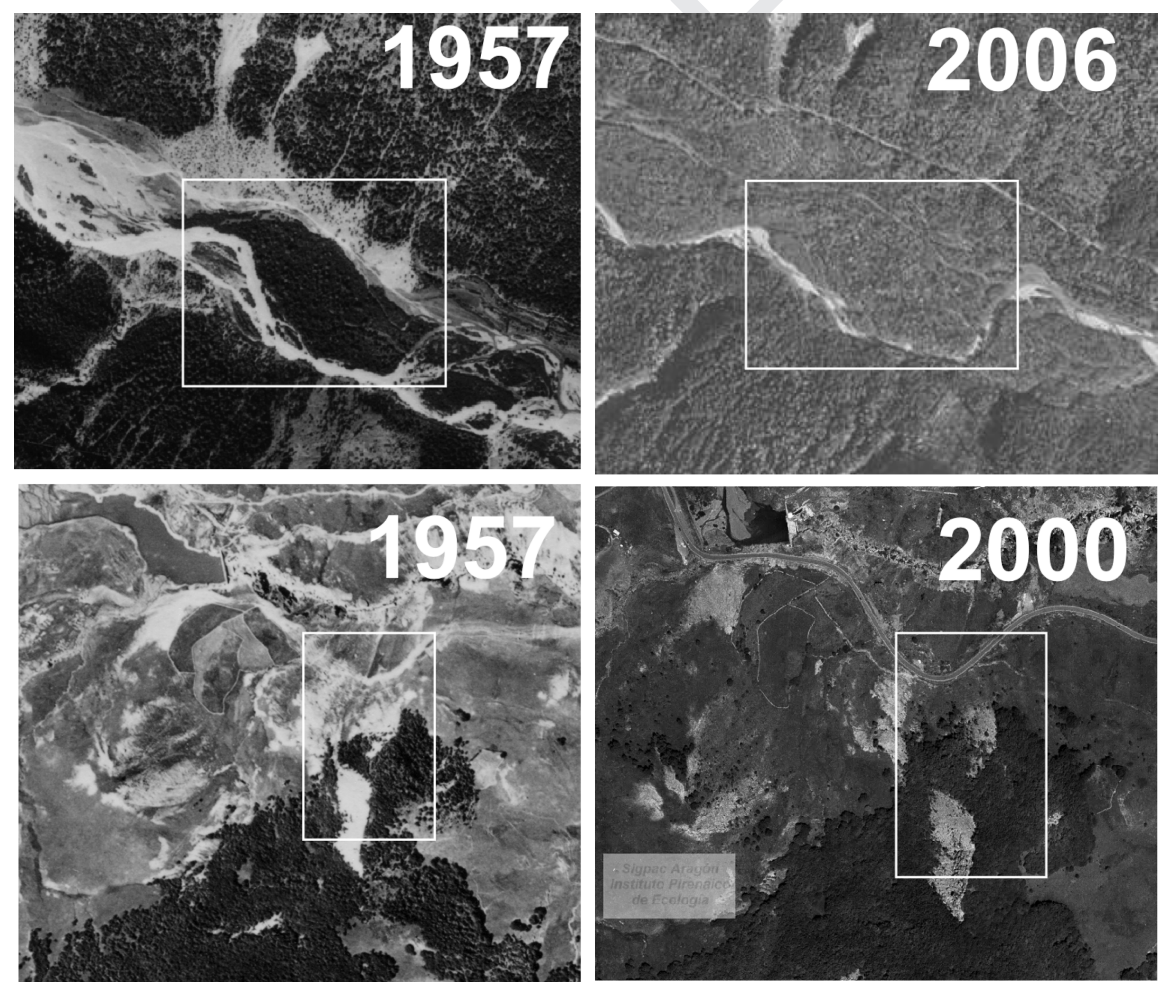

Figure 5. Changes in babitat of the two largest populations of lady slipper monitored (pictures on top; Pineta; pictures on bottom, Sallent; white squares, areas of population occurrence; darkest gray, forest; white, bare soil; other shading, grassland). 
open habitats by woody species has on population demography of herbs (Lehtilä et al. 2006; Andrieu et al. 2007) can shift in some situations, such as the one we investigated here, and counteract range-edge effects and other negative local factors. Forest expansion resulting from ongoing changes in the traditional land use of southern European countries has a negative effect on habitats of high diversity such as subalpine grasslands, but may also provide opportunities for species distributed mainly at higher latitudes. In the central Pyrenees for example, where this study was carried out, more than $100 \mathrm{Eu}-$ rosiberian forest herbs are in this situation (M.B.G. \& D. Gómez, unpublished data).

Our study does not provide evidence that the situation for lady slippers is deteriorating at one of the most peripheral areas of its wide distribution or that the situation for those populations is relatively worse than for populations at the center of the species' range. Overall, the performance of the studied populations seemed more related to local factors such as population size and recovery of the main habitat in which the species occurs than to their marginal position in the distribution area. In the absence of severe anthropogenic disturbances, the near future of the peripheral populations we studied appears favorable. Determining to what extent the pattern we found for lady slippers holds for other forest species at the southern portion of their ranges is an exciting future task because it may give some hope for survival of some species despite the global scenario of lower diversity under future conditions.

\section{Acknowledgments}

E. Andrés, R. Antor, F. Frutos, I. Jolly, C. Lahoz, D. Moreno, J. M. Navarro, J. Navas, and C. Tuda provided key information or assisted during the fieldwork over years. J. M. Olessen kindly drew Fig. 2, and P. Errea and J. Martínez assisted with Fig. 5. J. Bascompte, A. Diez, D. Doak, J. Ehrlén, and J. M. Iriondo provided very useful comments and linguistic advice. M. Alcántara, J. Guiral, I. Insausti, and J. Puente supported this study from the Regional Government through a European LIFE project (B4-3200/96/503). A National Spanish project funded the analysis and writing of this paper (CGL2006-08507).

\section{Supporting Information}

Original matrices are available as part of the online article (Appendix S1). The authors are responsible for the content and functionality of these materials. Queries (other than absence of the material) should be directed to the corresponding author.

\section{Literature Cited}

Andrieu, E., J. D. Thompson, and M. Debussche. 2007. The impact of forest spread on a marginal population of a protected peony (Paeonia officinalis L.): the importance of conserving the habitat mosaic. Biodiversity and Conservation 16:643-665.

Angert, A. L. 2006. Demography of central and marginal populations of monkeyflowers (Mimulus cardinalis and M. lewisii). Ecology 87:2014-2025.

Brzosko, E. 2002. Dynamics of island populations of Cypripedium calceolus in the Biebrza river valley (north-east Poland). Botanical Journal of the Linnean Society 139:67-77.

Caswell, H. 2001. Matrix population models: construction, analysis, and interpretation. 2nd edition. Sinauer Associates, Sunderland, Massachusetts.

Dorken, M. E., and C. G. Eckert. 2001. Severely reduced sexual reproduction in northern populations of a clonal plant, Decodon verticillatus (Lythraceae). Journal of Ecology 89:339-350.

Erneberg, M., and B. Holm. 1999. Bee size and pollen transfer in Cypripedium calceolus (Orchidaceae). Nordic Journal of Botany 19:363-367.

García, M. B., D. Guzmán, and D. Goñi. 2002. An evaluation of the status of five threatened plant species in the Pyrenees. Biological Conservation 103:151-161.

García, M. B., F. X. Picó, and J. Erhlén. 2008. Life span correlates with population dynamics in perennial herbaceous plants. American Journal of Botany 95:258-262.

Hampe, A., and R. Petit. 2005. Conserving biodiversity under climate change: the rear edge matters. Ecology Letters 8:461-467.

Hultén, E., and M. Fries. 1986. Atlas of north european vascular plants. North of the Tropic of Cancer. Maps 1-996. Koeltz Scientific Books, Königstein, Germany.

IUCN (International Union for Conservation of Nature). 2001. IUCN red list categories and criteria. Version 3.1. IUCN Species Survival Commission, Gland, Switzerland.

Korczynski, M., and E. R. Spiewakowski. 1991. Struktura rozmieszczenia I wielkosci populacji obuwika pospolitego Cypripedium calceolus L. nad jeziorem kwiecko (woj. Koszalinskie). Pradnik Prace Muzeum Szafera 3:183-191.

Jongejans E., and H. de Kroon. 2005. Space versus time variation in the population dynamics of three co-occurring perennial herbs. Journal of Ecology 93:681-692.

Jump, A. S., and F. I. Wookward. 2003. Seed production and population density decline approaching the range-edge of Cirsium species. New Phytologist 160:349-358.

Kull, T. 1995. Genet and ramet dynamics of Cypripedium calceolus in different habitats. Abstracta Botanica 19:95-104.

Kull, T. 1998. Fruit-set and recruitment in populations of Cypripedium calceolus L. in Estonia. Botanical Journal of the Linnean Society 126:27-38.

Kull, T., and M. J. Hutchings. 2006. A comparative analysis of decline in the distribution ranges of orchid species in Estonia and the United Kingdom. Biological Conservation 129:31-39.

Lammi, A., P. Siikamäki, and K. Mustajärvi. 1999. Genetic diversity, population size, and fitness in central and peripheral populations of a rare plant Lychnis viscaria. Conservation Biology 13:1069-1078.

Lazare, J. J., J. Miralles, and L. Villar. 1987. Cypripedium calceolus L. (Orchidaceae) en el Pirineo. Anales del Jardín Botánico de Madrid 43:375-382.

Lehtilä, K., K. Syrjänen, R. Leimu, M. B. García, and J. Ehrlén. 2006. Habitat change and demography of Primula veris: identification of management targets. Conservation Biology 20:833-843.

Lesica, P., and F. W. Allendorf. 1995. When are peripheral populations valuable for conservation? Conservation Biology 9:753-760.

Menges, E. S. 1997. Evaluating extinction risks in plant populations Pages 49-65 in P. L. Fiedler and P. M. Kareiva, editors. Conservation biology for the coming decade. Chapman and Hall, New York. 
Menges, E. S., and R. W. Dolan. 1998. Demographic viability of populations of Silene regia in midwestern prairies: relationships with fire management, genetic variation, geographic location, population size and isolation. Journal of Ecology 86: 63-78.

Menges, E. S., and D. R. Gordon. 1996. Three levels of monitoring intensity for rare plant species. Natural Areas Journal 16:227-237.

Morris, W., and D. F. Doak. 2002. Quantitative conservation biology. Sinauer, Sunderland.

Nantel, P., and D. Gagnon. 1999. Variability in the dynamics of northern peripheral versus southern populations of two clonal plant species, Helianthus divaricatus and Rbus aromatica. Journal of Ecology 87:748-760.

Nicolè, F., E. Brozosko, and I. Till-Bottraud. 2005. Population viability analysis of Cypripedium calceolus in a protected area: longevity, stability and persistence. Journal of Ecology 93:716-726.

Reier, Ü., E.-L. Tuvi, M. Pärtel, R. Kalamees, and M. Zobel. 2005. Threatened herbaceous species dependent on moderate forest distur- bances: a neglected target for ecosystem-based silviculture. Scandinavian Journal of Forest Research 20:145-152.

Sagarin, R. D., and S. D. Gaines. 2002. The "abundant centre" distribution: to what extent is it a biogeographical rule? Ecology Letters 5:137-147.

Sagarin, R. D., S. D. Gaines, and B. Gaylord. 2006. Moving beyond assumptions to understand abundant distributions across the ranges of species. Trends in Ecology and Evolution 21:524530.

Samis, K. E., and C. R. G. Eckert. 2007. Testing the abundant center model using range-wide demographic surveys of two coastal dune plants. Ecology 88:1747-1758.

Shefferson, R. P., T. Kull, and K. Tali. 2005. Adult whole-plant dormancy induced by stress in long-lived orchids. Ecology 86:3099-3104.

Terschuren, J. 1999. Action plan for Cypripedium calceolus in Europe. Nature and environment no. 100. Council of Europe Publishing, LOCATION NEEDED. 